\title{
Integrated quality strategy in production and raw material replenishment in a manufacturing-oriented supply chain
}

\author{
Rached Hlioui $^{\mathrm{a}}$, Ali Gharbi ${ }^{\mathrm{a}}$, Adnène Hajji ${ }^{\mathrm{b}}$ \\ a \\ Department of Automated Production Engineering, Production System and Control Laboratory, École de \\ technologie supérieure. University of Quebec, Montreal, QC, Canada \\ ${ }^{\mathrm{b}}$ Department of Operations and Decision Systems \& CIRRELT, Laval University, Quebec, QC, Canada
}

\section{Abstract:}

This paper deals with the coordination of production, replenishment and inspection decisions for a manufacturing-oriented supply chain with a failure-prone transformation stage, random lead-time and imperfect delivered lots. Upon reception of the lot, the manufacturer executes an acceptance sampling plan with a zero nonconforming criterion. If the sample does not contain non-conforming items, the lot is accepted; otherwise, it is rejected. In this work, two strategies regarding the refused sampled lot are studied. The first one involves a return of the lot to the supplier, who commits to improving the quality of the lot, while the second assumes that the manufacturer performs a 100\% inspection and rectification operation. This work presents two main objectives. The first one is to jointly optimize, in a stochastic and dynamic context, the ordering point of raw material, the lot size of raw material, the final product inventory threshold and the severity of the sampling plan using a simulation-based optimization approach. The second one is to determine the best of the two quality control strategy. The in-depth study has shown that no strategy could be preferred in all the cases. For this reasons, we present an easy decision-making tool (Indifference curves) to help the manager to select the best quality control strategy when considering the entire supply chain.

Keywords: Stochastic optimal control, Supply chain, Imperfect quality, Sampling plan, Manufacturing, Simulation, RSM. 


\section{Introduction}

In the literature, several authors have adopted feedback control policies to ensure better control of unreliable manufacturing systems. In this context, several approaches [1] have been developed based on the hedging point policy (HPP). This policy consists on building and maintaining an optimal safety stock level in order to continue to meet demand during the non-operational status of the manufacturing system. In the last decade, the HPP concept has evolved to specific areas to the case of more complex manufacturing problem context such as production, repair and replacement [2], remanufacturing [3], quality [4], environmental [5] and subcontracting [6].

Facing an uncertain environment, manufacturers are increasingly motivated by efficient coordination of their decisions. In fact, models incorporating raw material procurement in manufacturing activities perform better in terms of average total cost than those tackling the decisions involved separately [7]. In this context, Hajji et al. [8] addressed an integrated production and replenishment control problem in a three-stage supply chain with an unreliable transformation stage and supplier. Song [9] determined the optimal integrated ordering and production policy in a supply chain with stochastic lead-time, processing time and demand. Sana [10] presented an integrated productioninventory model for a three-layer supply chain considering perfect and imperfect quality items. He employed an analytical method to optimize the production rate and raw material order size for maximum expected average profit. Berthaut et al [11] considered a joint supply and remanufacturing activities and proposed a suboptimal control policy. Hajji et al [12] proposed a practical approach to the joint production and delayed supply control problem. Hajji et al. [13] developed a stochastic dynamic programming model to investigate a supplier selection problem, together with optimal controls on inventory replenishment and manufacturing activities. Pal et al. [14] optimized the production rate and raw material order size for a three-layer supply chain containing a supplier, a manufacturer and a retailer, where defective raw materials are sent back to the supplier and imperfect final products are reworked. Sana [15] developed an integrated economic production quantity and economic order quantity model for a three-layer supply chain subject to defective items in production and transportation, and determined the optimal 
production rate, order quantity, and number of shipments. Song [16] studied several stochastic supply chain systems and determined the optimal production and ordering control policies in the case of supply chains with backordering, a multistage serial supply chain, a supply chain with multiple products, and supply chains with assembly operations. Jana et al. [17] proposed to coordinate production and inventory decisions across a three-layer supply chain model under conditionally permissible delay in payments. More recently, Song et al. [18] determined the optimal integrated productioninventory control for a manufacturing supply chain with multiple suppliers in the presence of uncertain material suppliers, stochastic production times and random customer demands, using the stochastic dynamic programming approach. They also studied supplier issues, such as supplier base reduction and supplier differentiation, under the integrated inventory management policy.

From the above literature review, the production-inventory model for a three-stage supply chain adopted two main assumptions concerning the reaction of the manufacturer against the delivered lot: either there is no quality control due to the implicit assumption of perfect delivered raw materials $[8,16]$ or there is $100 \%$ screening $[15,14]$. In reality, a fraction of the received lot may consist of non-conforming parts, known as "items of poor quality" [19]. In that case, the inspection policy has to be integrated into the productioninventory model to reduce the impact of raw material non-conformity on ordering and lot sizing decisions [20] and on the quality of the finished product [21]. Given that a $100 \%$ inspection process may be costly and time consuming, an acceptance sampling plan could be more adequate.

The inspection of the delivered raw material with an acceptance sampling plan has been widely adopted in the industries. However, the research integrating sampling policy even with simple lot sizing has received very limited attention [22]. This paper considers a manufacturer-oriented supply chain system with a failure-prone transformation stage, a random lead-time and an imperfect delivered lot. Upon reception of the lot, the manufacturer performs a lot-by-lot single-sampling plan with a zero acceptance criterion applied. In fact, this kind of sampling plan is widely adopted in the aerospace manufacturing [23] and food industries, among pharmaceutical companies, fisheries [24] 
and electronic manufacturing processes [25]. If the sample does not contain nonconforming items, the lot is accepted; otherwise, the lot is rejected.

When the lot is rejected, some authors have examined the involvement of the supplier in their studies. Starbird [26] examined the effect of the buyer's rewards, penalties, and inspection policies on the behaviour of an expected cost minimizing supplier. Wan et al. [27] determined the acceptance sampling plan of the firm and the quality effort level of the supplier either in the simultaneous game or in the Stackelberg leadership game where both buyer and supplier share the inspection cost and the recall loss. However, to the best of our knowledge, in the case of the supplier-buyer relationship, authors have not considered that the returned lot may be inspected by the supplier, leading to an improvement of its quality. Other authors have assumed a $100 \%$ inspection on the refused lot. Ben-Daya, Noman [20],[28] studied an integrated inventory inspection models with and without replacement of non-confirming items. Moussawi-Haidar et al. [29] presented an analytical method to optimize the lot size, sample size and acceptance number in an EOQ-type model that achieves a certain average outgoing quality limit.

In this work, as a stochastic lead-time and a backlog cost of the final product are considered, the manufacturer may prefer to go with the $100 \%$ option, but with some corrective action, such as reworking the non-conforming items of the rejected lot, rather than returning it to the supplier. $100 \%$ option may ensure the presence of raw material and the continuity of the transformation process. However, if the supplier offers a certain degree of improvement of the lot whenever it is returned, the manufacturer could be attracted by this option. In fact, the return option may allow the manufacturer to deliver better quality and avoid additional inspection and rectification costs, but at the same time, it may lead to an increase in the delivery delay, which may in turn lead to the production system being starved of the raw material. In this case, the production process is stopped, causing an increase in the backlog costs of the final product due to the presence of customer demand. For these reasons, it is important to study the different strategies regarding the refused lots.

We formulate, in a stochastic and dynamic context, the integrated production, replenishment and quality control decision making problem. In the second part of this 
work, we propose integrated decision strategies capable of dealing with coordination within the considered supply chain. A simulation model and a response surface methodology are then applied to find the optimal parameters governing the proposed decision strategies. An in-depth study is also conducted regarding the two proposed policies (return and 100\% inspection) following the lot rejection.

The rest of this paper is organized as follows. Section 2 presents the notation and the problem statement. Section 3 reports the control policy. Section 4 illustrates the resolution approach. The simulation model is presented in section 5. A numerical example is delivered in section 6 to outline the usefulness of the proposed control policy. Sensitivity analyses are discussed is section 7 . The decision making choice regarding the rejected lot and the effects of the supplier's involvements are studied in section 8. Finally, the paper is concluded in section 9 .

\section{Notation and problem statement}

\subsection{Notation}

The notations used in the paper are defined as follows.

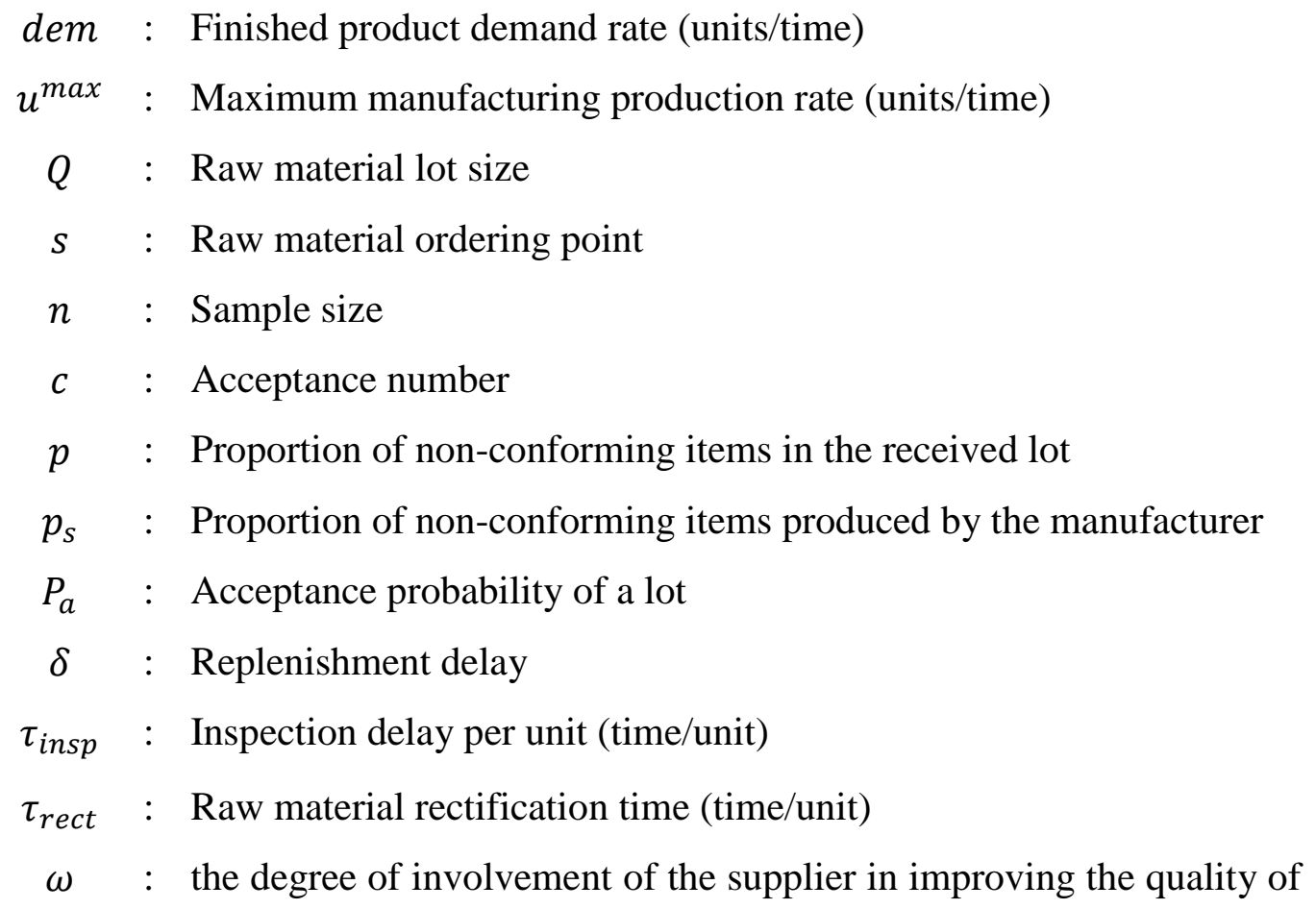




$$
\text { a rejected lot }
$$

$\begin{array}{lll}\gamma & \text { the number of times that the lot is rejected by the manufacturer } \\ c_{R}^{H} & : \text { Raw material holding cost (\$/time/unit) } \\ c_{F}^{H} & : \text { Finished product holding cost (\$/time/unit) } \\ c_{F}^{B} & : \text { Finished product backlog cost (\$/time/unit) } \\ c_{\text {insp }} & : \text { Raw material inspection cost (\$/unit) } \\ c_{r e c t}^{R} & : \text { Raw material rectification cost (\$/unit) } \\ c_{\text {remp }}^{F} & : \text { Non-conforming finished product replacement cost (\$/unit) }\end{array}$

\subsection{Problem statement}

We consider a three-stage supply chain with one supplier, one manufacturer and one customer. The manufacturer could be unavailable due to failures and repair operations. The supplier takes an order of raw materials with quantity $Q$ and supplies it to the manufacturer after a random shipment delay $\delta$. It is assumed that each delivered lot contains a percentage, denoted $p$, of non-conforming items.

Upon reception, the manufacturer applies a lot-by-lot single acceptance sampling plan with attributes to control the quality of the received lot. This plan is characterised by a sample of size $n$ and a zero acceptance number $(c=0)$. After inspecting a random sample $n$, the manufacturer decides to accept this lot, if the number of nonconforming $d=0$, or to refuse it, if $d>0$. In this situation, the manufacturer's decision could be expressed by the probability of acceptance $P_{a}$ [24], which is given as follows:

$$
P_{a}=(1-p)^{n}
$$

In this paper, we consider that the accepted lot is immediately placed in the raw materials stock. Concerning the rejected lot, the manufacturer will face two options:

- Option1 (RET $(\omega)$ policy): the supplier proposes to improve the quality of each rejected lot by applying an additional control operation (Fig.1- Option 1). Let us denote by $\omega(0 \leq \omega \leq 1)$ the degree of involvement of the supplier in improving the quality of this lot, and $\gamma$ the number of times that the lot is rejected by the manufacturer. In other words, if $\omega=1$, the supplier undertakes to perform a 
$100 \%$ inspection of each refused lot. And, if $\omega=0$, no inspection operation is undertaken by the supplier. After an additional shipment delay $\delta$, this lot will be delivered with a new percentage of non-conforming items $p_{(\gamma=1)}=p \cdot(1-\omega)$. At the reception, the lot will be inspected and the manufacturer decides to accept or to refuse it. If the lot is rejected again, the supplier will improve its quality and the new percentage of non-conforming items will be $p_{(\gamma=2)}=p .(1-\omega)^{2}$. Then, the percentage of $p_{\gamma}$ varies according to the following relationship:

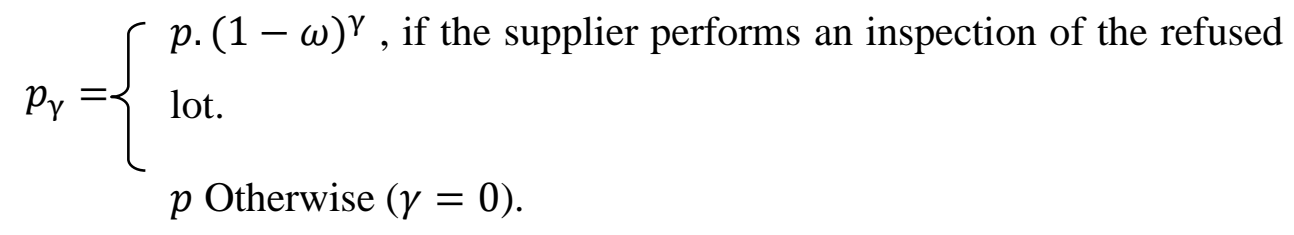

- Option 2 (100\% policy): the rejected lot is submitted to $100 \%$ inspection. We consider that all non-conforming items in lot $Q$ are rectified with a $\tau_{\text {rect }}$ delay per unit and $c_{\text {rect }}^{R}$ cost per unit (Fig.1- Option 2).

The raw material (RM) held in the manufacturer's warehouse incurs a holding $\operatorname{cost} c_{R}^{H}$ per item per unit time. The manufacturer produces a single type of finished product to respond to the continuous and constant demand rate "dem". It is assumed that the production process may produce a proportion $p_{s}$ of non-conforming final product items. The holding cost of the final product (FP) for the manufacturer is $c_{F}^{H}$ per item per unit time. However, if the manufacturer could not respond to the customer demand, a backlog cost $c_{F}^{B}$ per item per unit time is considered. Because some non-conforming product could be sold to the final customer, it is assumed that the customer can detect and return it to be replaced with a $c_{r e m p}^{F}$ per unit cost.

The whole state of the considered supply chain at time $t$ is described by a hybrid state combining a discrete component, $\alpha(t)$, and two continuous components $y(t)$ and $x(t)$. The discrete component represents the state of the transformation stage, and can be classified as "manufacturing system is available", denoted by $\alpha(t)=1$, or "manufacturing system is unavailable", denoted by $\alpha(t)=2$. The first 
continuous element $y(t)$ represents the stock level of the finished product. It can be positive, for an inventory, or negative, for a backlog. Further, the second one, $x(t)$, represents the stock level of the raw material $(x(t) \geq 0)$.

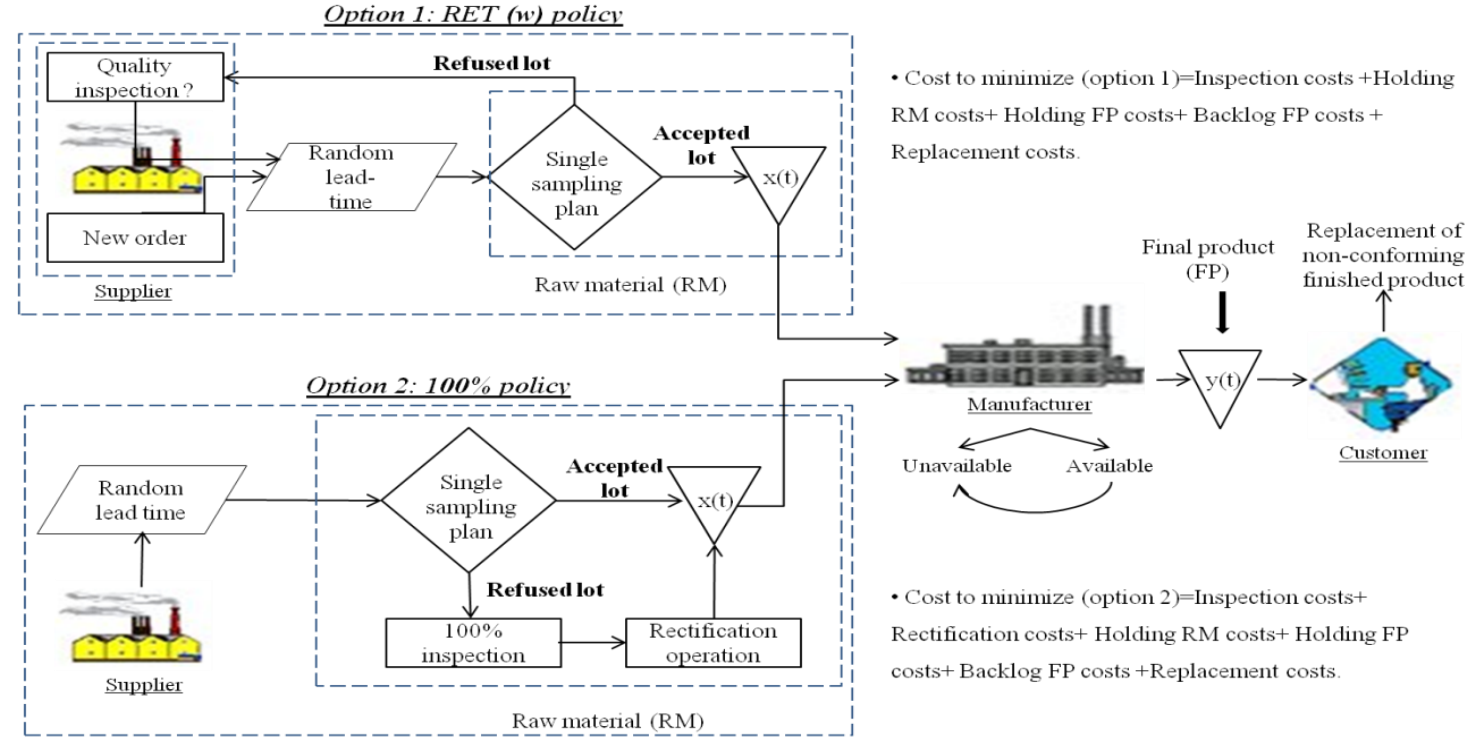

Fig. 1: Supply chain under study

In this case, the dynamics of the stock level is given by the following differential equations:

$$
\begin{gathered}
\dot{y}(t)=u(t, \alpha)-\frac{d e m}{(1-A O Q) \cdot\left(1-p_{s}\right)}, y(0)=y_{0} \quad \forall t \geq 0 \\
\left.\dot{x}(t)=-u(t, \alpha), x(0)=x_{0} \forall t \in\right] \xi_{i}, \xi_{i+1}[ \\
x\left(\xi_{i}^{+}\right)=x\left(\xi_{i}^{-}\right)+Q_{i} \forall i=1 \ldots N
\end{gathered}
$$

where $y_{0}, x_{0}$ represents the initial stock levels, $u(t, \alpha)$ denotes the manufacturing system production rate in mode $\alpha$, dem denotes the demand rate, $A O Q$ represents the average outgoing quality of the raw material, and $\xi_{i}^{-}, \xi_{i}^{+}$represent the negative and positive boundaries of the $N$ receipt instants after an inspection operation, respectively.

According to the inspection policy, the average outgoing quality of the raw material $A O Q$ can be measured as follows [24]: 


$$
A O Q=\left\{\begin{array}{l}
A O Q_{100 \%}=P_{a} \cdot p \cdot\left(\frac{Q-n}{Q}\right) \\
A O Q_{R E T(\omega)}=p_{\gamma}
\end{array}\right.
$$

In a dynamic stochastic context, Hajji et al. [12] analysed this class of model, but without including an imperfect delivered raw material. Given the complex structure of the optimization equations, they first adopted a numerical approach to illustrate the structure of the integrated production and delayed replenishment control policy, and secondly, a simulation-based experimental approach to cover more complex situations. They showed that the optimal production strategy is defined by a Hedging Point Policy (HPP) and that the optimal replenishment strategy belongs to the class of $(s, Q)$ policies. The HPP policy consists in maintaining a surplus of products to be able to meet demand (dem) when the manufacturing system is unavailable due to machine failures. The $(s, Q)$ policy consists in ordering an economic lot $Q$ of raw materials when the upstream inventory level reaches $s$.

\section{Control policy}

The main objective of this work is to determine the production policy $u($.$) , the supply$ policy $\Omega$ and the best quality control policy (RET $(\omega)$ and 100\%). According to the findings of Hajji et al. [12], production and supply policies are defined by the Hedging Point Policy (HPP) and the $(s, Q)$ policy, respectively. However, by considering the effect of average total quality of the raw material $A O Q(t)$ on the real demand rate, a modified HPP may be more appropriate to illustrate our production policy.

The following structures of the production and supply policies, as well as the two

quality control policies, are proposed as follows, where $u^{\max }$ represents the maximum production rate, $s$ the ordering point, $Q$ the lot size, and $Z$ the final product hedging level. 


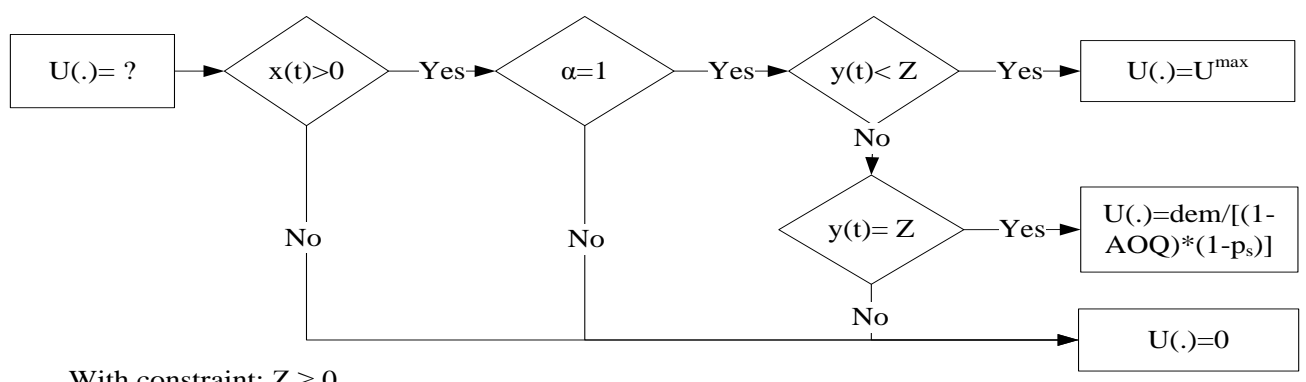

Fig. 2: Production policy (Modified Hedging Point Policy (MHPP))

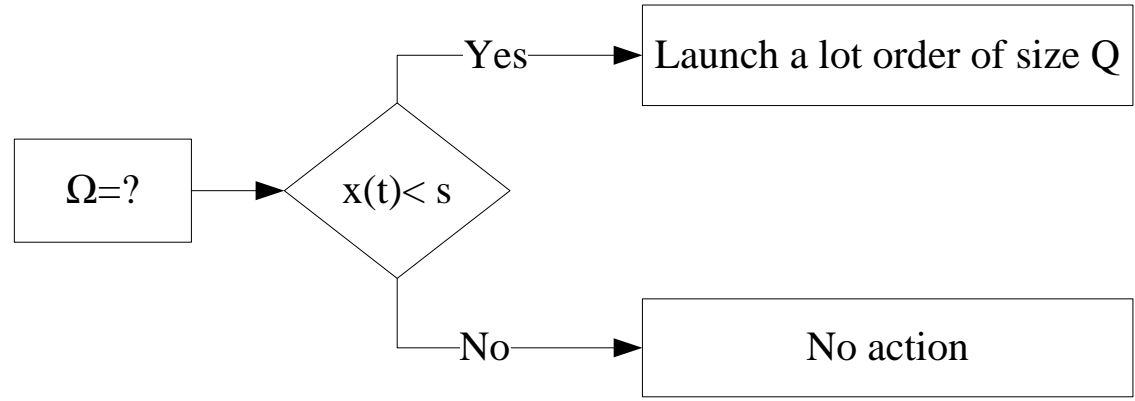

With constraint: $\mathrm{Q}>\mathrm{s} \geq 0$

Fig. 3: Supply policy (s, Q)

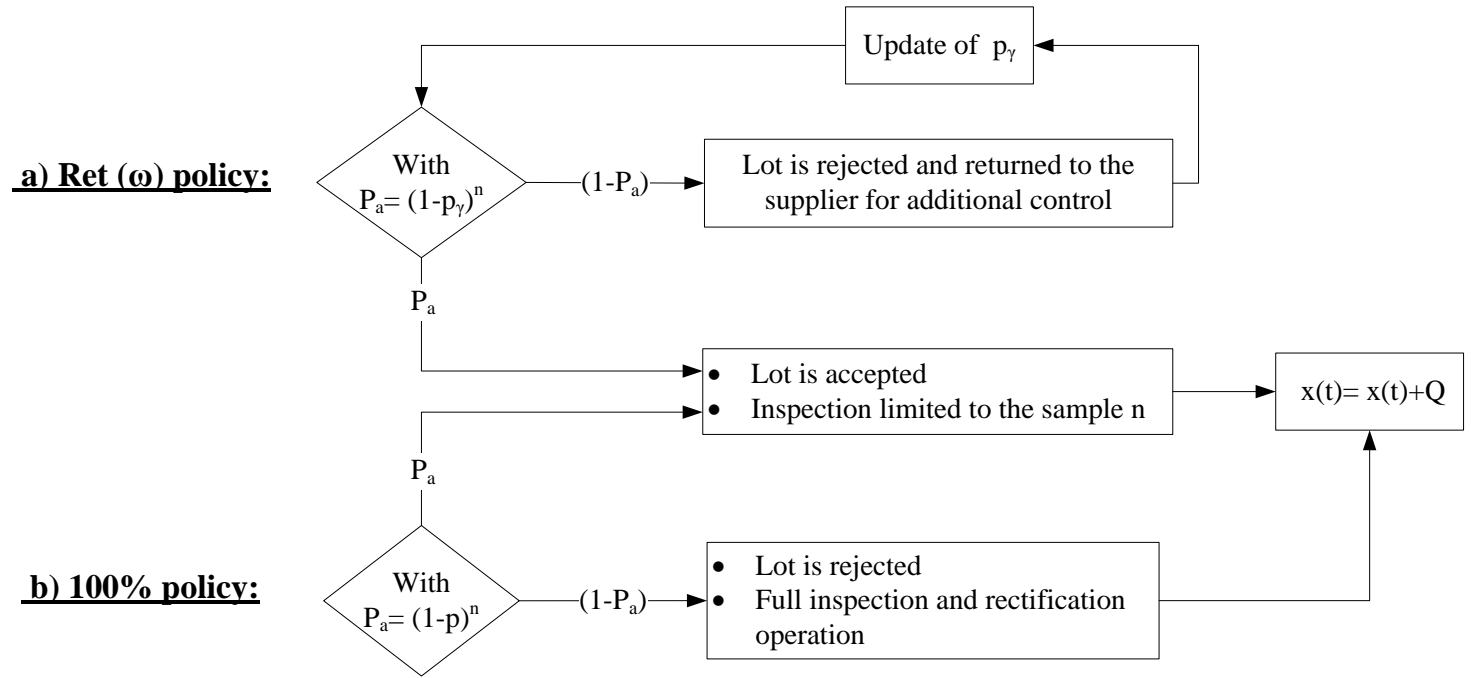

Fig. 4: Quality strategy

To illustrate the interaction of production, supply and inspection activities, Fig.5 presents graphically the evolution of the stock level of the raw material $x(t)$ and final product $y(t)$ when the manufacturer's inspection decision is to return the refused lot. 
1. When the $x(t)$ level crosses the ordering point (Arrow (1)), the manufacturer orders a new lot. Once the lot is delivered after $\delta$ delay, a sample size $\mathrm{n}$ is inspected with A delay. In this situation, if the lot is accepted, it is added to the final stock of RM (Arrow 2). Otherwise, the supplier picks it up and the manufacturer has to wait for an additional lead-time $\delta$ (Arrow 3 ).

2. At the same time, when the production system and RM are available, the RM is transformed to FP at the maximal rate (Arrow ${ }^{4}$ ) whenever $y(t)$ is below $Z$, and at an adjusted demand (Arrow 5 ) rate whenever $y(t)$ is equal to $Z$.

3. The production process is stopped for two reasons. The first one (Arrow 6 ) is the unavailability of the manufacturer stage. The second one (Arrow 7 ) is the out-ofstock RM state $(x(t)=0)$. Since the manufacturer faces a continuous demand, a backlog of FP may arise (Arrow 7 ) depending on the state of the entire chain and quality decisions.

— Finished product inventory $\mathrm{y}(\mathrm{t})$

- Raw material inventory $\mathrm{x}(\mathrm{t})$
A Sampling inspection delay

$\delta$ : Replenishment delay

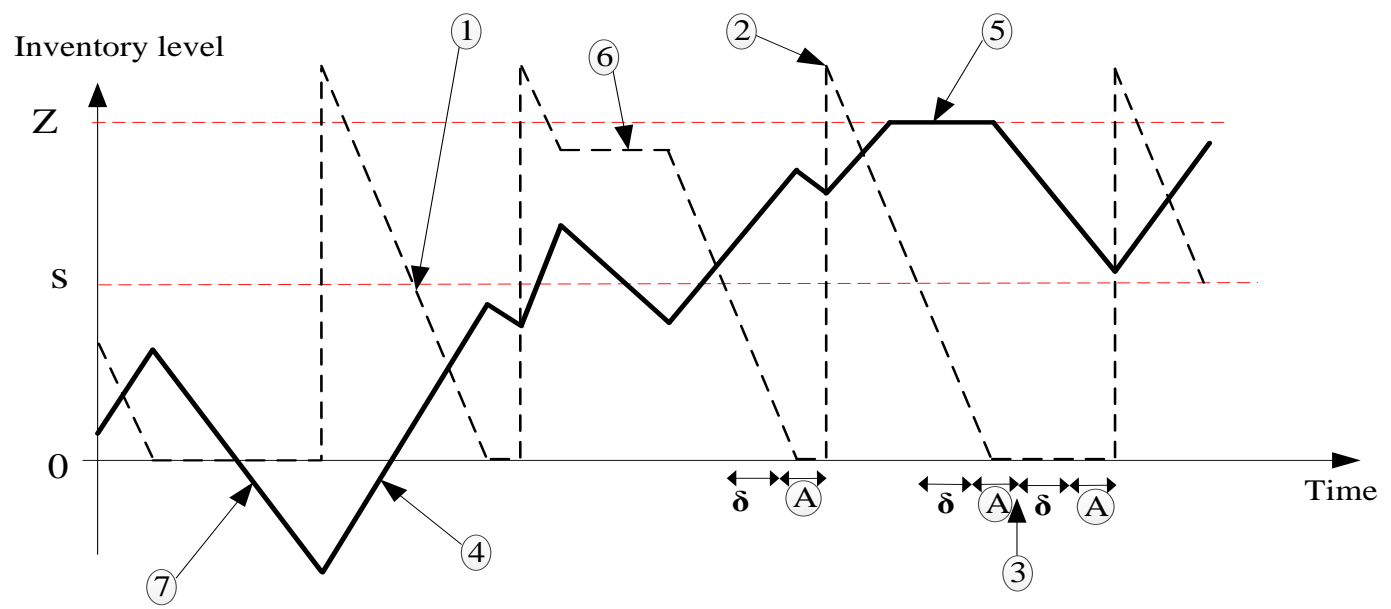

Fig. 5: Evolution of raw material and finished product inventory under the joint production, supply and Ret inspection policies

In this study, our decision variables are the sample size $n$, the final product hedging level $Z$ and the supply policy $(s, Q)$. Given the complex structure of the considered system, we propose to determine experimentally the optimum control parameters 
$(s, Q, Z, n)$ that give the best approximation of the long-term expected total cost consisting of the raw material holding cost, the finished product holding/backlog costs, the sampling costs, the costs of $100 \%$ inspection and rectification (Case $100 \%$ policy), and the cost of replacing non-confirming finished products.

\section{Resolution approach}

A simulation-based optimization method is adopted. This approach combines simulation modelling, experimental design and Response Surface Methodology. This approach was applied in different field such as production control problem[30] and an integrated production, overhaul and preventive maintenance problem [31]. The structure of the proposed control approach is as follows:

I. Based on the developed control policy presented previously, a simulation model is developed to describe the dynamics of each integrated production, replenishment and quality problem. Therefore, the total incurred cost is obtained for the given value of the control policy (Fig. 2 - Fig. 4).

II. An appropriate experimental design approach defines how control factors can be varied in order to identify the effects of the main factors and their interactions on the response (the incurred cost).

III. The Response Surface Methodology (RSM) is used to determine the relationship between the incurred cost and the significant main factors and/or interactions. From this estimated relation, the optimal values of the control policy parameters, called $\left(s^{*}, Q^{*}, Z^{*}, n^{*}\right)$ and the optimal cost value are determined.

\section{Simulation model}

To represent the dynamic behaviour of the considered supply chain, two simulation models were developed using the SIMAN simulation language (ARENA simulation software) with $\mathrm{C}++$ subroutines, where a combined discrete/continuous model is adopted according to the considered quality policy. Indeed, using such a combined approach

allows us to reduce the execution time and secure more flexibility than with a purely discrete model [32]. The first model reproduces the integrated production-replenishment- 
raw material quality control policy when the RET $(\omega)$ is adopted. The second model reproduces the integrated policies when the $100 \%$ is selected. Fig. 6 presents the overall model structure used in each of the two model

1. The INITIALIZATION block initializes the values of the joint production replenishment and quality control policy $(s, Q, Z, n)$ and the problem variables, such as the initial states $\left(x_{0}, y_{0}\right)$, production rates, inspection parameters, the replenishment lead-time, and the number of rejections of the same lot $\gamma^{i}$. We also assign the simulation time $T_{\infty}$ at this step such that the steady-state is reached.

2. The PRODUCTION CONTROL POLICY block (1) sets the production rates according to Fig. 2. This block relates to the "Update finished product inventory level" block 2 in charge of raising a FLAG whenever the FP inventory level crosses the threshold $(Z)$.

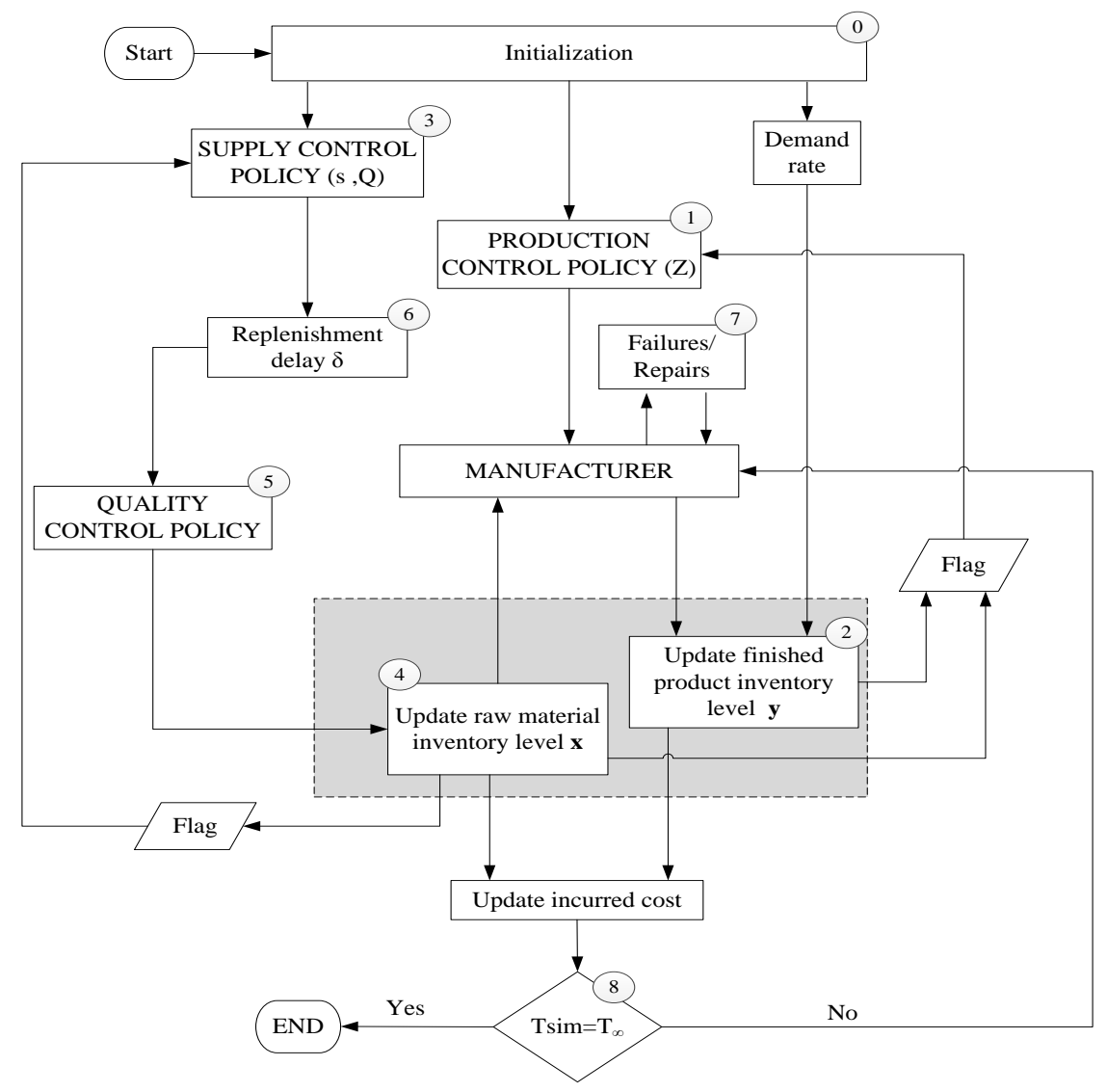

Fig. 6: Simulation block diagram 
3. The SUPPLY CONTROL POLICY block 3 sets the order quantities according to Fig. 3. This block relates to the "Update raw material inventory" block 4 in charge of raising a FLAG whenever the raw material inventory level crosses the threshold s.

4. The QUALITY CONTROL POLICY block 5 sets the inspection policy according to Fig. 4. (a or b). When the lot is delivered after a lead-time 6, a sample size is inspected. The decision of the inspector is modelled by a probabilistic BRANCH block of SIMAN, which represents the probability of acceptance $\mathrm{P}_{\mathrm{a}}$ (Eq. 1). Indeed, $\mathrm{P}_{\mathrm{a}}$ lots are accepted and $\left(1-\mathrm{P}_{\mathrm{a}}\right)$ lots are rejected. If the lot is accepted, the average outgoing quantity AOQ(.) is updated according to Eq. 5. If the lot is refused, and depending on the adopted quality policy, the proportion of non-conforming items $\mathrm{p}$ in a lot is updated according to Eq. 2 (case of RET policy) or the lot is $100 \%$ inspected and all non-conforming items are rectified (case of $100 \%$ policy). Once the quality control is completed, the lot is added to the raw materials stock and then the stock level is updated (Eq. 4).

5. The FAILURES AND REPAIRS block 7 models the manufacturing system failure and repair events as a closed loop following the time to failure (TTF) and the time to repair (TTR) distributions, respectively. The operational states of the manufacturing system are incorporated in the state equations (Eq. 3) (defined as a $\mathrm{C}$ language insert) through binary variables, which multiplies the production rates.

6. Finally, when the current time of the simulation $\mathrm{T}_{\operatorname{Sim}}$ reaches $\mathrm{T}_{\infty} 8$, the simulation is stopped.

\section{Experimental results}

In this section, we apply the procedure outlined in the previous section. The purpose is firstly, to find out whether the input parameters $(s, Q, Z, n)$ affect the response (the cost), and then develop a regression equation. Secondly, the optimal parameter values of the two proposed policies (RET $(\omega)$ and 100\%) and the optimal expected cost are determined. Finally, a sensitivity analysis is conducted to show the robustness of the 
policies and highlight important features. The values of the operational and cost parameters, characterising the supply chain and inspection operations, are given in Tables 1 and 2:

Table 1: Cost and production parameters

\begin{tabular}{|c|c|c|c|c|c|c|c|c|c|c|}
\hline Parameter & $u^{\text {max }}$ & dem & $T T F$ & $T T R$ & $c_{R}^{H}$ & $c_{\text {insp }}$ & $c_{F}^{H}$ & $c_{F}^{B}$ & $c_{\text {remp }}^{F}$ & $c_{\text {rect }}^{R}$ \\
\hline Values & 300 & 180 & Expo(15) & Expo(1.65) & 5 & 18 & 5 & 150 & 1300 & 350 \\
\hline
\end{tabular}

Table 2: Inspection and delay (per day) parameters

\begin{tabular}{|c|c|c|c|c|c|c|c|c|}
\hline Parameter & $c$ & $p$ & $p_{s}$ & $\omega$ & $\delta$ & $\tau_{\text {insp }}$ & $\tau_{\text {rect }}$ & $T_{\infty}$ \\
\hline Values & 0 & $2.5 \%$ & $1 \%$ & 1 & $\begin{array}{c}\text { Expo } \\
(1.5)\end{array}$ & 0.00025 & 0.012 & $10^{6}$ \\
\hline
\end{tabular}

\subsection{Experimental design}

Since we have four dependent parameters $(s, Q, Z, n)$, a Face-Centered Central Composite design FCCCD is used for the design of experiments. This experimental design is built by $2^{4}$ factorial design with 8 star points and 4 center points. In fact, a 2level factorial design augmented with center and axis points presents a desirable plan [33] thanks to its two main characteristics: orthogonality and rotatability. For more details, we refer the reader to [34]. Five replications were conducted for each combination of factors, and therefore, $140(28 * 5)$ simulation runs were conducted. In addition, we used the "common random number" technique [35] to reduce the variability in the response.

\subsection{Statistical analysis and response surface methodology}

The statistical analysis of the simulated data consists of the multi-factor analysis of the variance (ANOVA). Indeed, it provides the effects of the independent variables $(\mathrm{s}, \mathrm{Q}, \mathrm{Z}, \mathrm{n})$ on the dependent variable (the cost). Using a statistical software application such as STAGRAPHICS, we note that all the $\mathrm{R}_{\text {adj }}^{2}$ values (Table 3 and Table 4) are greater than 95\%; over $95 \%$ of the total variability is thus explained by the models [34]. Furthermore, we can see from Table 3 and Table 4 that all "P-values" are below the 0.05 level. This observation leads us to conclude that the main factors $(s, Q, Z$ and $n)$ of the 
different policies, their quadratic effects $\left(s^{2}, Q^{2}, Z^{2}\right.$ and $\left.n^{2}\right)$, as well as their interactions (s. Q, s.Z, s.n, Q.Z,Q.n and Z.n), are significant for the response variable at a $5 \%$ level of significance.

Table 3: ANOVA Table case of $100 \%$ policy

\begin{tabular}{|c|c|c|c|c|c|}
\hline Source & $\begin{array}{c}\text { Sum of } \\
\text { Squares }\end{array}$ & Df & $\begin{array}{c}\text { Mean } \\
\text { Square }\end{array}$ & F-Ratio & P-Value \\
\hline$s$ & 717976. & 1 & 717976. & 87.40 & 0.0000 \\
\hline$Q$ & 601711. & 1 & 601711. & 73.25 & 0.0000 \\
\hline$Z$ & 369242. & 1 & 369242. & 44.95 & 0.0000 \\
\hline$n$ & $8.53866 \mathrm{E} 6$ & 1 & $8.53866 \mathrm{E} 6$ & 1039.42 & 0.0000 \\
\hline$s^{2}$ & 445062. & 1 & 445062. & 54.18 & 0.0000 \\
\hline$s . Q$ & $2.58683 \mathrm{E} 6$ & 1 & $2.58683 \mathrm{E} 6$ & 314.90 & 0.0000 \\
\hline$s . Z$ & $2.89968 \mathrm{E} 6$ & 1 & $2.89968 \mathrm{E} 6$ & 352.98 & 0.0000 \\
\hline$s . n$ & 550718. & 1 & 550718. & 67.04 & 0.0000 \\
\hline$Q^{2}$ & 396640. & 1 & 396640. & 48.28 & 0.0000 \\
\hline$Q . Z$ & 976364. & 1 & 976364. & 118.85 & 0.0000 \\
\hline$Q . n$ & 182246. & 1 & 182246. & 22.18 & 0.0000 \\
\hline$Z^{2}$ & 206016. & 1 & 206016. & 25.08 & 0.0000 \\
\hline$Z . n$ & 128052. & 1 & 128052. & 15.59 & 0.0001 \\
\hline$n^{2}$ & $1.04891 \mathrm{E} 6$ & 1 & $1.04891 \mathrm{E} 6$ & 127.68 & 0.0000 \\
\hline blocks & 350868. & 5 & 70173.5 & 8.54 & 0.0000 \\
\hline Total error & $1.2158 \mathrm{E} 6$ & 148 & 8214.87 & & \\
\hline Total (corr.) & $3.39646 \mathrm{E} 7$ & 167 & \multicolumn{5}{|l|}{$R_{a j s}^{2}=95.96 \%$} \\
\hline & & & &
\end{tabular}

Table 4: ANOVA Table case of RET (1) policy

\begin{tabular}{|c|c|c|c|c|c|}
\hline Source & $\begin{array}{c}\text { Sum of } \\
\text { Squares }\end{array}$ & Df & $\begin{array}{c}\text { Mean } \\
\text { Square }\end{array}$ & F-Ratio & P-Value \\
\hline$s$ & $4.26806 \mathrm{E} 6$ & 1 & $4.26806 \mathrm{E} 6$ & 113.39 & 0.0000 \\
\hline$Q$ & 560629. & 1 & 560629. & 14.89 & 0.0002 \\
\hline$Z$ & $3.80976 \mathrm{E} 7$ & 1 & $3.80976 \mathrm{E} 7$ & 1012.11 & 0.0000 \\
\hline$n$ & $2.84027 \mathrm{E} 6$ & 1 & $2.84027 \mathrm{E} 6$ & 75.46 & 0.0000 \\
\hline$s^{2}$ & $1.72016 \mathrm{E} 6$ & 1 & $1.72016 \mathrm{E} 6$ & 45.70 & 0.0000 \\
\hline$s . Q$ & $6.20745 \mathrm{E} 6$ & 1 & $6.20745 \mathrm{E} 6$ & 164.91 & 0.0000 \\
\hline$s . Z$ & $3.19623 \mathrm{E} 7$ & 1 & $3.19623 \mathrm{E} 7$ & 849.12 & 0.0000 \\
\hline$s . n$ & 808343. & 1 & 808343. & 21.47 & 0.0000 \\
\hline$Q^{2}$ & 301942. & 1 & 301942. & 8.02 & 0.0053 \\
\hline$Q . Z$ & $5.30167 \mathrm{E} 6$ & 1 & $5.30167 \mathrm{E} 6$ & 140.85 & 0.0000 \\
\hline$Q . n$ & 280499. & 1 & 280499. & 7.45 & 0.0071 \\
\hline$Z^{2}$ & $1.2139 \mathrm{E} 7$ & 1 & $1.2139 \mathrm{E} 7$ & 322.49 & 0.0000 \\
\hline$Z . n$ & 406586. & 1 & 406586. & 10.80 & 0.0013 \\
\hline$n^{2}$ & 681559. & 1 & 681559. & 18.11 & 0.0000 \\
\hline Blocks & 411926. & 5 & 82385.3 & 2.19 & 0.0585 \\
\hline Total error & $5.57096 \mathrm{E} 6$ & 148 & 37641.6 & & \\
\hline Total (corr.) & $1.73599 \mathrm{E} 8$ & 167 & & & \\
\hline & & & $R_{a j s}^{2}=96.37 \%$ \\
\hline
\end{tabular}

A residual analysis was conducted to verify the adequacy of the models. In fact, a residual versus predicted value plot and normal probability plot were analysed to confirm the homogeneity of residuals and normality assumption, respectively.

From STATSGRAPHICS, the response surface of each policy is given by:

$$
\begin{aligned}
& \operatorname{Cost}_{100 \%}(s, Q, Z, n)=40195-27.7545 . s-7.65011 . Q-18.6135 . Z- \\
& \text { 1.3429.n+0.010853. } s^{2}+0.00375206 . s . Q+0.00926912 . s . Z- \\
& \text { 0.00721339.s.n+0.00130684. } Q^{2}+0.00192093 . Q . Z-0.00148199 . Q . n \\
& +0.00512779 . Z^{2}-0.00289859 . Z . n+0.0368954 . n^{2} . \\
& \operatorname{Cost}_{R E T(1)}(s, Q, Z, n)=45884.5-23.72 . s-7.95014 . Q-24.6895 . Z- \\
& \text { 10.2199.n+0.00644144.s }{ }^{2}+0.00298063 . s . Q+0.0072466 . s . Z- \\
& \text { 0.00896331.s.n+0.000993255.Q } Q^{2}+0.00179049 . Q . Z-0.00320322 . Q . n \\
& +0.00722965 . Z^{2}-0.004132 . Z . n+0.103631 . n^{2} .
\end{aligned}
$$


The optimal solution for each quality strategy is presented in table 5.

Furthermore, to crosscheck the validity of these solutions, for each quality strategy, $\left(s^{*}, Q^{*}, Z^{*}, n^{*}\right)$ were used as input to the simulation model representing this strategy. The cost value obtained falls in the 95\% confidence (Eq. 8; with $m=20$ extra replications). From Table 5, it can be seen that the obtained cost of each quality strategy falls within the confidence interval:

$$
\bar{C}^{*}(m) \pm t_{\frac{\alpha}{2}}, \boldsymbol{m - 1} \cdot \sqrt{S^{2}(m) / m}
$$

where $\overline{\mathrm{C}}^{*}$ is the average obtained cost, $S$ the sample standard deviation, and $(1-\alpha)$ the confidence level.

Table 5 Optimal parameters, cost and confidence interval results

\begin{tabular}{|c|c|c|c|c|c|c|}
\hline \multirow{2}{*}{ Policy } & \multicolumn{4}{|c|}{ Optimal Parameters } & \multirow{2}{*}{ Optimal Cost } & \multirow{2}{*}{ CI (95\%) } \\
\cline { 2 - 5 } & $S^{*}$ & $Q^{*}$ & $Z^{*}$ & $\mathrm{n}^{*}$ & & \\
\hline $100 \%$ & 674.06 & 1307 & 1003.25 & 150 & 16404 & {$[16399.19,16462.62]$} \\
\hline RET (1) & 896.19 & 1926 & 1059.49 & 139 & 13808.1 & {$[13751.7,13821.28]$} \\
\hline
\end{tabular}

In this section, we determined the optimal parameter value and the optimal expected cost for the $100 \%$ policy and RET (1) policies. This case study shows that the decision maker has to choose the RET (1) policy rather than the $100 \%$ policy. By choosing the RET (1) policy, we note up to $14.4 \%$ cost savings $\% \Delta \mathrm{C}^{*}=14.4 \%$, where $\% \Delta \mathrm{C}^{*}=$ $\left[\left(\mathrm{C}_{100 \%}^{*}-\mathrm{C}_{\mathrm{RET}(\omega)}^{*}\right) / \mathrm{C}_{100 \%}^{*}\right]$. These savings express the percentage of the relative gain that the manufacturer can enjoy if the RET (1) policy is selected.

\section{Sensitivity analysis}

To properly understand the effect of a given parameter variation on the integrated production, supply and quality control policy, and to make sense of all these effects, a set of numerical examples were considered to measure the sensitivity of the obtained control policy. The following variations (Table 6) are explored and compared to the basic case of the RET (1) policy. 


\subsection{Case 1: Variation of the raw material holding $\operatorname{cost} c_{R}^{H}$}

When the $c_{R}^{H}$ cost increases (respectively decreases), the optimal ordering point $s^{*}$ and lot size $Q^{*}$ decreases (respectively increases) to reduce (respectively increase) the stock level of RM. In this case, the manufacturer promotes (respectively demotes) first the transformation of RM to $\mathrm{FP}$, where the optimal hedging level $Z^{*}$ increases (respectively decreases) and second the acceptance decision of a delivered lot, where the sample size $n^{*}$ decreases (respectively increases).

Table 6: Sensitivity analysis data and results of Ret $(\omega)$ policy

\begin{tabular}{|c|c|c|c|c|c|c|c|c|}
\hline \multirow{2}{*}{ Case } & \multirow{2}{*}{ Parameter } & \multirow{2}{*}{ Variation } & \multicolumn{4}{|c|}{ Optimal Parameters } & \multirow{2}{*}{ Cost $^{*}$} & \multirow{2}{*}{ Impact on } \\
\hline & & & $\mathrm{s}^{*}$ & $\mathrm{Q}^{*}$ & $\mathrm{Z}^{*}$ & $\mathrm{n}^{*}$ & & \\
\hline Base & - & - & 896.19 & 1926 & 1059.49 & 139 & 13808.1 & - \\
\hline \multirow[t]{2}{*}{1} & \multirow{2}{*}{$c_{R}^{H}$} & 2.5 & 1104.44 & 2129 & 929.36 & 146 & 11248.6 & $\begin{array}{c}\mathrm{S}^{*} \uparrow \mathrm{Q}^{*} \uparrow Z^{*} \downarrow \\
\mathrm{n}^{*} \uparrow \text { Cost }^{*} \downarrow\end{array}$ \\
\hline & & 7.5 & 845 & 1576 & 1129.45 & 135 & 15846.3 & $\begin{array}{c}\mathrm{s}^{*} \downarrow Q^{*} \downarrow Z^{*} \uparrow \\
n^{*} \downarrow \operatorname{Cost}^{*} \uparrow\end{array}$ \\
\hline \multirow[t]{2}{*}{2} & \multirow{2}{*}{$c_{F}^{H}$} & 2.5 & 780 & 1830 & 1501.23 & 136 & 11079.2 & $\begin{array}{c}\mathrm{s}^{*} \downarrow Q^{*} \downarrow Z^{*} \uparrow \\
n^{*} \downarrow \text { Cost }^{*} \downarrow\end{array}$ \\
\hline & & 7.5 & 995.36 & 1945 & 843.48 & 140 & 1587.4 & $\begin{array}{c}\mathrm{S}^{*} \uparrow \mathrm{Q}^{*} \uparrow \mathrm{Z}^{*} \downarrow \\
\mathrm{n}^{*} \uparrow \mathrm{Cost}^{*} \uparrow\end{array}$ \\
\hline \multirow[t]{2}{*}{3} & \multirow{2}{*}{$c_{F}^{B}$} & 100 & 835.13 & 1850 & 854.85 & 137 & 12991.8 & $\begin{array}{c}\mathrm{s}^{*} \downarrow Q^{*} \downarrow Z^{*} \downarrow \\
n^{*} \downarrow \text { Cost }^{*} \downarrow\end{array}$ \\
\hline & & 200 & 957.13 & 1974 & 1109.52 & 140 & 14298.2 & $\begin{array}{c}\mathrm{S}^{*} \uparrow \mathrm{Q}^{*} \uparrow \mathrm{Z}^{*} \uparrow \\
\mathrm{n}^{*} \uparrow \mathrm{Cost}^{*} \uparrow\end{array}$ \\
\hline \multirow[t]{2}{*}{4} & \multirow{2}{*}{$\mathrm{C}_{\text {insp }}$} & 15 & 905.52 & 1895 & 1059.62 & 142 & 13728.7 & $\begin{array}{c}\mathrm{S}^{*} \uparrow \mathrm{Q}^{*} \downarrow Z^{*} \uparrow \\
\mathrm{n}^{*} \uparrow \text { Cost }^{*} \downarrow\end{array}$ \\
\hline & & 20 & 890.37 & 1945 & 1059.26 & 137 & 13859.3 & $\begin{array}{c}\mathrm{S}^{*} \downarrow \mathrm{Q}^{*} \uparrow \mathrm{Z}^{*} \downarrow \\
\mathrm{n}^{*} \downarrow \operatorname{Cost}^{*} \uparrow\end{array}$ \\
\hline \multirow[t]{2}{*}{5} & \multirow{2}{*}{$\delta$} & Expo(1) & 542.74 & 1680 & 929.62 & 138 & 11780.6 & $\begin{array}{c}\mathrm{s}^{*} \downarrow Q^{*} \downarrow Z^{*} \downarrow \\
n^{*} \downarrow \text { Cost }^{*} \downarrow\end{array}$ \\
\hline & & Expo(2) & 1270.44 & 2396 & 1138.56 & 166 & 15708.2 & $\begin{array}{c}\mathrm{S}^{*} \uparrow \mathrm{Q}^{*} \uparrow \mathrm{Z}^{*} \uparrow \\
\mathrm{n}^{*} \uparrow \mathrm{Cost}^{*} \uparrow\end{array}$ \\
\hline \multirow{3}{*}{6} & \multirow{3}{*}{$\omega$} & 0.8 & 1041.52 & 1984 & 1101.43 & 85 & 15840.6 & \multirow{3}{*}{$\begin{array}{c}\mathrm{s}^{*} \uparrow \mathrm{Q}^{*} \uparrow \mathrm{Z}^{*} \uparrow \\
\mathrm{n}^{*} \downarrow \mathrm{Cost}^{*} \uparrow\end{array}$} \\
\hline & & 0.6 & 1267.7 & 2042 & 1062.42 & 76 & 17195.1 & \\
\hline & & 0.2 & 548.68 & 1453 & 1002.44 & 1 & 17373.5 & \\
\hline
\end{tabular}

7.2. Case 2: Variation of the finished product holding $\operatorname{cost} \mathrm{c}_{\mathrm{F}}^{\mathrm{H}}$

When the $c_{F}^{H}$ cost increases, the level $Z^{*}$ decreases to reduce the FP inventory costs. By reducing the transformation of the RM, the system will make creates more RM stocks ( $s^{*}$ and $Q^{*}$ increase), and with better quality ( $n^{*}$ increases), to be used when required. When the $c_{F}^{H}$ cost decreases, we note an opposite variation of the optimal parameters. 


\subsection{Case 3: Variation of the finished product backlog $\operatorname{cost} \mathrm{c}_{\mathrm{F}}^{\mathrm{B}}$}

When increasing the $c_{F}^{B}$ cost, the values of all the decisions variable $s^{*}, Q^{*}, Z^{*}$ and $n^{*}$ increase. In fact, the manufacturer must keep a significant stock level ( $Z^{*}$ increases) with better quality ( $n^{*}$ increases) to limit the risk of shortage. The increase in the supply parameters aims to reduce the stock-out RM frequency due to the presence of the lead-time and inspection decision. In the opposite case ( $c_{F}^{B}$ decreases), we have an opposite effect on the different optimal parameters.

\subsection{Case 4: Variation of the inspection cost $c_{\text {insp }}$}

When the inspection cost $c_{\text {insp }}$ increases, the system tends to reduce the total inspection cost by decreasing the optimal sample size $n^{*}$. This variation leads to an increase in the $P_{a}$ probability, and then to an increase in the acceptance frequency for the supplied lot. As result, the FP level $Z^{*}$ decreases due to the decrease in the RM stock-out frequency. Regarding the supply parameters, $s^{*}$ decreases and $Q^{*}$ increases to avoid a high level of RM stock. The decrease in inspection cost produces the opposite effects.

\subsection{Case 5: Variation of the lead-time $\delta$}

When the $\delta$ increases (respectively decreases), $s^{*}$ and $Q^{*}$ increase (respectively decrease) to ensure a higher (respectively lower) RM stock level. Facing an increased (respectively decreased) supplied lot size, the system decreases (respectively increases) the $P_{a}$ probability by increasing (respectively reducing) the sample size $n^{*}$. At the same time, the $Z^{*}$ level increases (respectively decreases) to face the RM stock-out frequency (respectively availability).

\subsection{Case 6: Variation of the degree of supplier's involvement $\omega$}

When the degree of supplier involvement $\omega$ decreases, the system promotes an acceptance decision by increasing the acceptance probability $P_{a}$ ( $n^{*}$ decreases). This effect must be balanced by higher supply parameters $\left(s^{*}\right.$ and $Q^{*}$ increase) to maintain an appropriate RM availability. In this situation, the level $Z^{*}$ increases to face the stock-out and the reduction of the product quality. 
It is interesting to note that when the degree of the supplier involvement $\omega$ is very low $(\omega=0.2)$, the system determines that the supplier involvement is not enough to offset the effect of additional delivery delay. The system will then prefer to omit the return policy of a rejected inspected lot by maximizing the acceptance probability $P_{a}$. This trend is illustrated by the optimal sample size $n^{*}=1$.

Through this analysis, we can conclude the following: Firstly, we have confirmed that varying the control parameters evolves as expected with respect to parameter variations. Secondly, given the economic challenges at play, it is important to coordinate quality control for the delivered lot with production and replenishment activities. By choosing the RET policy, gains obtained can be up to $15 \%$ compared to the $100 \%$ policy. Finally, it is important to consider the sample size as a control parameter for the integrated production-supply-raw material quality control problem. In fact, the determination of the optimal sample size parameter provides the decision maker with the possibility of varying the severity of the inspection plan. This parameter can be set to $n^{*}=1$ where there is maximum acceptance of delivered batches.

From Table 6 (case 6), we observe that when the degree of involvement $\omega$ of the supplier decreases, the optimal expected cost increases. This variation causes a decrease in the cost saving $\% \Delta \mathrm{C}^{*}$ (Table 7 ), which influences the decision maker in his choice of the $100 \%$ or the RET $(\omega)$ policy. In fact, when $\% \Delta C^{*}>0$, the decision maker has to select the return policy. However, if $\% \Delta \mathrm{C}^{*}<0$, the $100 \%$ policy must be selected. In the next section, a detailed comparative study between these two policies is conducted to highlight the main aspects differentiating them.

Table 7: $\% \Delta \mathrm{C}^{*}$ variation

\begin{tabular}{|c|c|c|c|c|}
\hline$\omega$ & 1 & 0.8 & 0.6 & 0.2 \\
\hline$\% \Delta \mathrm{C}^{*}$ & $14.4 \%$ & $3.4 \%$ & $-4.8 \%$ & $-9.4 \%$ \\
\hline
\end{tabular}

\section{Comparative study between $100 \%$ and RET ( $\omega$ ) strategies}

The objective of this section is to conduct an in-depth comparative study in order to determine the best quality policy in terms of cost. Even if the preference of the decision 
maker depends essentially on the degree of involvement of the supplier $\omega$, other parameters (such as the proportion of non-conforming items $p$ and the lead-time $\delta$ ) may have a significant influence on the manufacturer choice.

Fig. 7 and Fig. 8 illustrate the variation of cost saving $\% \Delta \mathrm{C}^{*}$ depending on the quality of the delivered lot $\mathrm{p}$ and the lead-time $\delta$, respectively. The different steps performed to establish Fig. 7 (respectively, Fig. 8) are as follows: For each percentage of nonconforming items $p$ (respectively, lead-time $\delta$ ), we first determined the optimal parameter value and the optimal expected cost for the $100 \%$ policy. Secondly, we determined the optimal parameter value and the optimal expected cost for the RET $(\omega)$ policy, for different degrees of involvement $\omega$. The cost saving $\% \Delta \mathrm{C}^{*}$ was then calculated as in the previous sections.

\subsection{Effect of $p$}

From Fig. 7, we note that the decision maker may have more than one decision to make, depending on $p$ values:

- $p=1 \%$ : RET $(\omega)$ and $100 \%$ policies should be avoided. We notice that $\% \Delta \mathrm{C}^{*}=$ $0 \%, \forall \omega \in[0,1]$. In fact, this observation is illustrated through the optimization of the different control parameters, where the optimal sample size $n^{*}$ is equal to 1 . When it encounters a good quality lot, the system tries to maximize the probability of acceptance $P_{a}$ and then encourages the decision maker to omit the inspection operation and its involvement to avoid additional delays and costs caused either by a return decision or a $100 \%$ inspection and rectification operation.

- $p=1.5 \%$ : The RET $(\omega)$ policy is more advantageous than the $100 \%$ policy only for a certain value of $\omega$. The system still considers that quality of the delivered lot is good. As a result, the system tries to maximize the probability of acceptance $P_{a}$ and then encourages the decision maker to omit additional inspection costs caused by a $100 \%$ inspection and rectification operation. This decision is in keeping with the policy to return the inspected lot when the degree of involvement of the 
supplier $\omega$ is low. However, from a certain degree of $\omega(\omega>0.78)$, the systems prefers the return policy to ensure better performance of the supply chain.

- $p \geq 2.5 \%$ : The RET $(\omega)$ or $100 \%$ policy may be selected. The $\% \Delta \mathrm{C}^{*}$ curve shows a switching point $\omega_{s}$ of decision for which $\% \Delta \mathrm{C}^{*}=0 \%$ (no preference for a specific quality policy). Fig. 7 shows also that when the percentage of nonconforming items $p$ increases, the $\omega_{\mathrm{s}}$ value decreases (for $p=2.5 \%, \omega_{\mathrm{s}}=0.74$; for $\left.p=3.5 \%, \omega_{\mathrm{s}}=0.68\right)$. This is explained by the need to avoid incurring additional significant rectification costs due to the presence of more nonconforming items in the lot. For the remaining values of $\omega$, the decision maker has to select the RET $(\omega)$ policy, if $\% \Delta \mathrm{C}^{*}>0 \%$, and the $100 \%$ policy, if $\% \Delta \mathrm{C}^{*}<0 \%$.

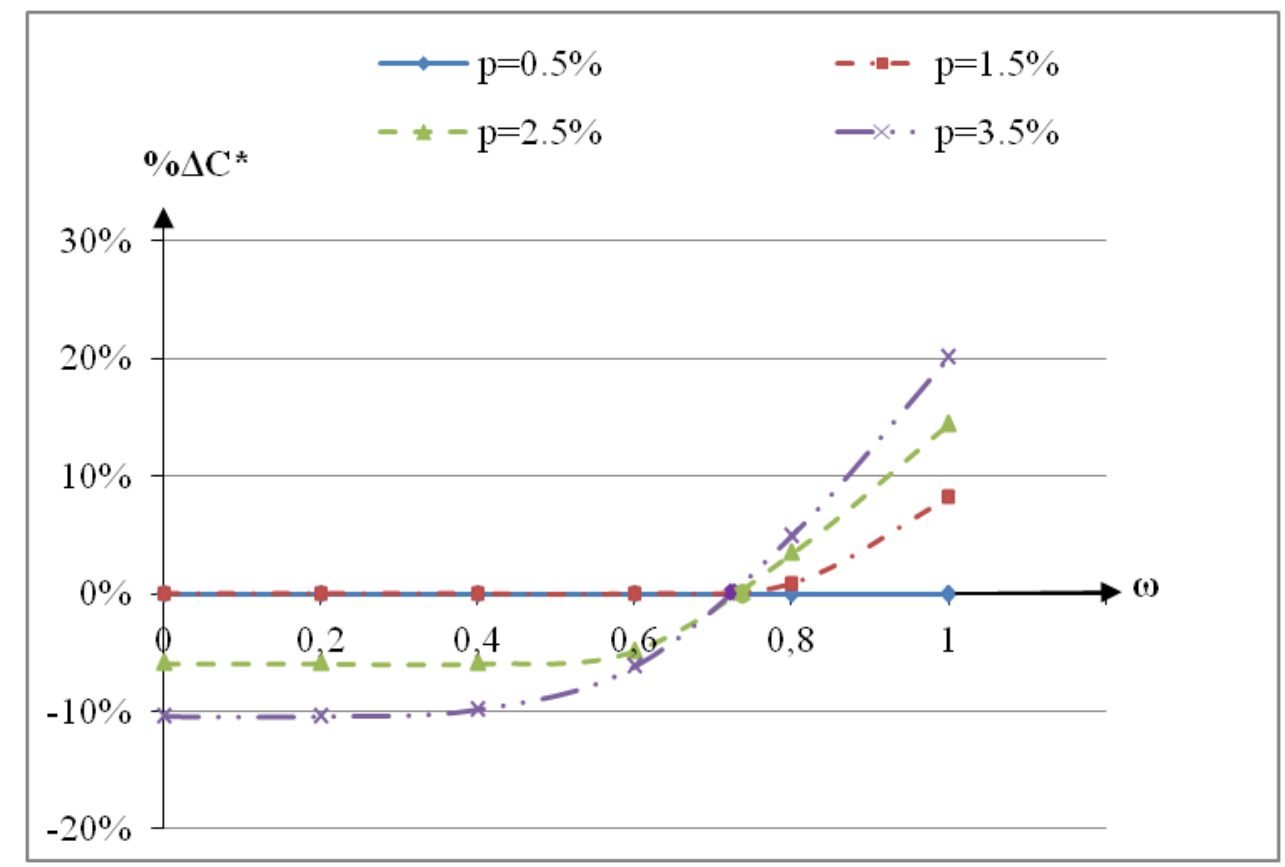

Fig. 7: $\% \Delta C^{*}=f(\omega)$ with different values of $p, c_{i n s p}=18 \$ / u, \delta=$ Expo (1.5)

\subsection{Effect of $\delta$}

From Fig. 8, we note that, depending on the $\delta$ value, the decision maker may decide as follows:

- $\delta=$ Expo (3.5): Only one inspection policy may be selected, and the return policy should not be taken ( $\left.\% \Delta \mathrm{C}^{*}<0 \%, \forall \omega \in[0,1]\right)$. To avoid an increase in the RM 
stock-out frequency, an increase in the risk of stoppage of the production process and then, an increase in the final product backlog cost, the decision maker must choose the $100 \%$ inspection and rectification operation policy.

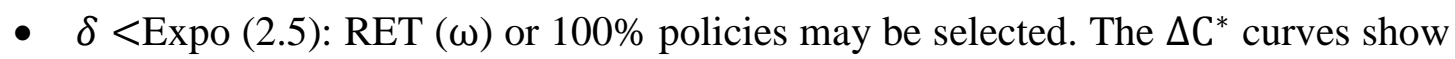
a switching point $\omega_{\mathrm{s}}$ of decision for which $\% \Delta \mathrm{C}^{*}=0 \%$. It can be seen that when the lead-time $\delta$ decreases, the $\omega_{\mathrm{s}}$ value decreases. Indeed, when $\delta$ is low, the decision maker will accept a lower level of involvement of the supplier. For the remaining values of $\omega$, the decision maker must select the return policy, if $\% \Delta \mathrm{C}^{*}>0 \%$ and the $100 \%$ policy, if $\% \Delta \mathrm{C}^{*}<0 \%$.

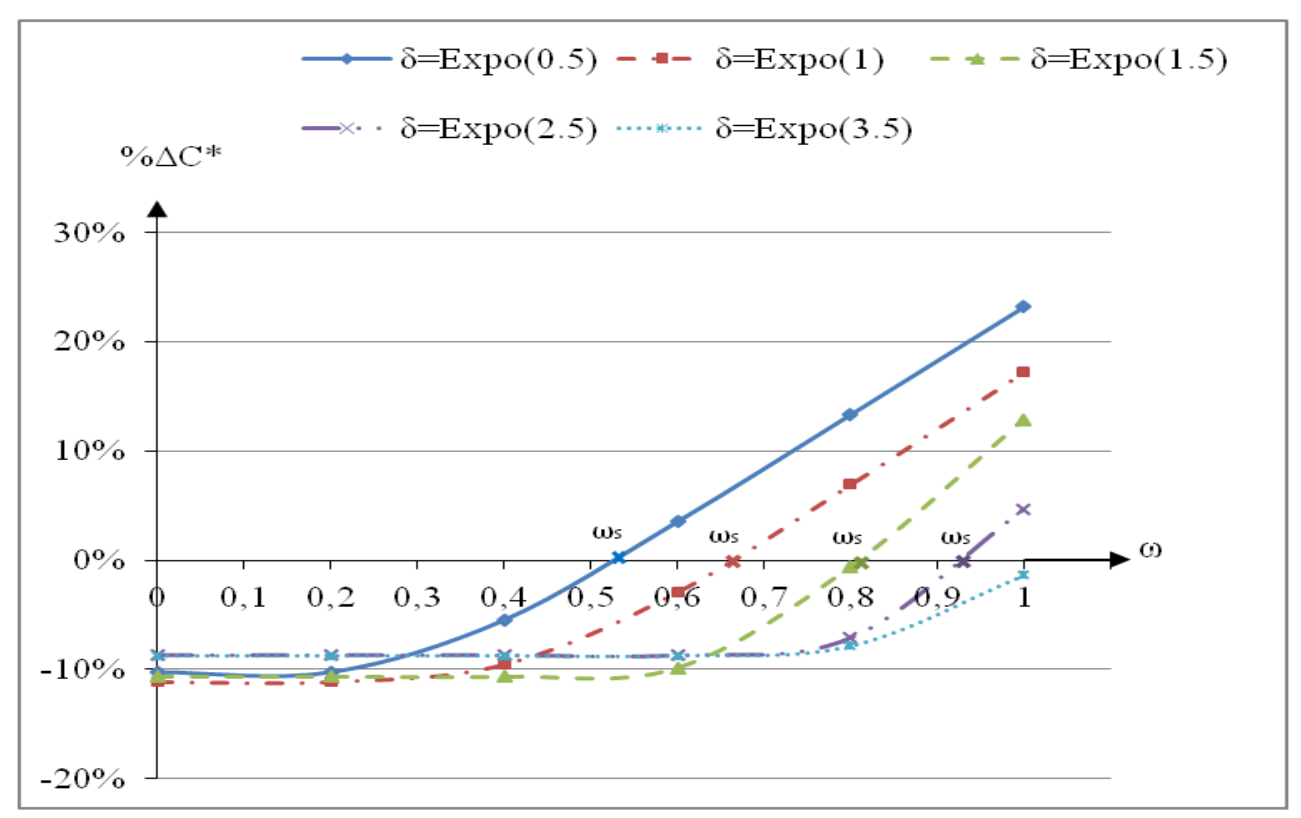

Fig. 8: $\% \Delta C^{*}=f(\omega)$ with different value of lead-time $\delta$, case $c_{i n s p}=14 \$ / u, p=2.5 \%$

\subsection{Effect of $\mathrm{c}_{\mathrm{insp}}$ and $\mathrm{c}_{\mathrm{F}}^{\mathrm{B}}$}

Fig. 7 and Fig. 8 showed that $\omega_{s}$ values vary depending on the supply chain parameters. In fact, the latter represents the minimum implication degree that the supplier must provide so that the return policy ensures better results. To select the most economic policy, we present in Fig. 9 the indifference curves for lead-time $\delta$ and degree of involvement of the supplier $\omega$.This curve devises the area in two zones which present whether or not to choose the $100 \%$ policy as the best quality control policy. 
Fig.9.a shows the effect of the inspection $\operatorname{cost} c_{\text {insp }}$ variation on the indifference curve. It can be seen that when $c_{i n s p}$ increases from $14 \$ / u$ to $22 \$ / u$, the area in which a return policy is more advantageous increases. Indeed, this variation is explained by the tendency of the system to avoid greater total inspection costs. The decrease in the $c_{\text {insp }} \operatorname{cost}$ produces the opposite effect. Fig. 9.b shows the effect of the finished product backlog $\operatorname{cost} c_{F}^{B}$ variation on the indifference curve. It can be seen that when $c_{F}^{B}$ increases from $100 \$ /$ day/u to $400 \$ /$ day/u, the area where the $100 \%$ inspection and rectification operation policy is more advantageous increases. Indeed, this variation is explained by the tendency of the system to avoid the risk of stoppage of the production process due to RM stock-out caused by delivery times. The decrease in $c_{F}^{B}$ cost produces the opposite effect.

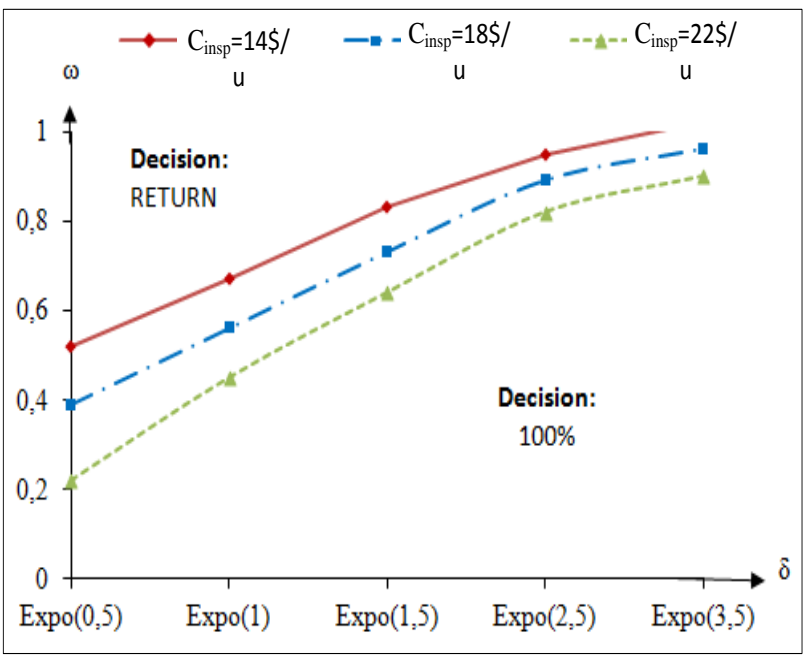

(a): For different value of $c_{\text {insp }}$

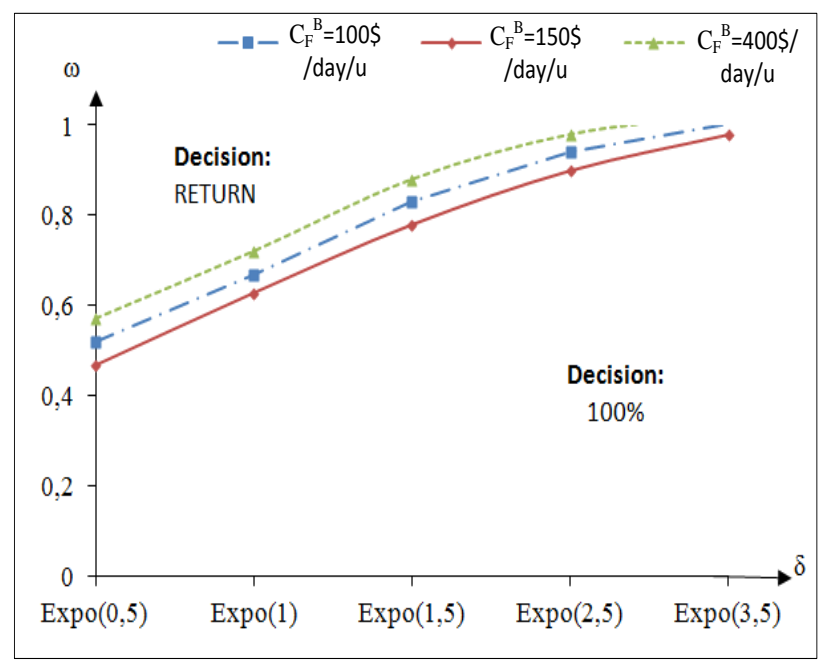

(b): For different value of $\mathrm{c}_{\mathrm{F}}^{\mathrm{B}}$

Fig. 9: Indifference curve for lead-time $\delta$ and degree of involvement of the supplier $\omega$,

$$
\mathrm{p}=2.5 \%
$$

\section{Conclusion}

In this work, the simulatneous production, replenishement and raw material quality control problem was addressed for the case of a manufacturing-oriented supply chain with a failure-prone transformation stage, random lead-time and imperfect delivered lot. Upon reception of the lot, the manufacturer performs an acceptance sampling plan with a zero non-conforming criterion applied. The problem was formulated in a stochastic dynamic context, where the production rate, the order quantity, the reorder point and the 
sample size are considered as decision variables. We focused first on the determination of the optimal control parameters, and secondly on the best quality control issues concerning the rejected sampled lot. Two quality policies were considered, with the first involving a return of the lot to the supplier who is committed to improve its quality, while the second assumed that the manufacturer executes a $100 \%$ inspection and rectification operation. An experimental approach based on simulation modelling, design of experiment and response surface methodology was applied to determine the parameters of the control policy involving the two quality policies.

This paper highlighted two interesting results. First, we observed that it is important to consider the sample size of the acceptance sampling plan as a control variable. In fact, depending on the entire supply chain parameters, this parameter varies the severity degree of the quality control at the reception to ensure the minimum total cost. Secondly, in the supply chain management context, the manufacturer must investigate both the $100 \%$ and return policies. Indeed, we showed that the different parameters of the supply chain and the degree of involvement of the supplier have a significant influence on the decision to be made following inspection.

In conclusion, the findings of this work set the stage for further studies, including other sampling policies, such as double sampling plans and selection between multiple suppliers. The evaluation and optimization of such a supply chain remains a challenging area.

\section{References}

1. Kenné JP, Gharbi A (2000) Production planning problem in manufacturing systems with general failure and repair time distributions. Production Planning \& Control 11 (6):581-588

2. Dehayem Nodem FI, Kenne JP, Gharbi A (2009) Hierarchical decision making in production and repair/replacement planning with imperfect repairs under uncertainties. European Journal of Operational Research 198 (1):173-189

3. Kenné JP, Dejax P, Gharbi A (2012) Production planning of a hybrid manufacturingremanufacturing system under uncertainty within a closed-loop supply chain. International Journal of Production Economics 135 (1):81-93

4. Bouslah B, Gharbi A, Pellerin R (2013) Joint optimal lot sizing and production control policy in an unreliable and imperfect manufacturing system. International Journal of Production Economics 144 (1):143-156 
5. Ben-Salem A, Gharbi A, Hajji A (2015) Environmental issue in an alternative production-maintenance control for unreliable manufacturing system subject to degradation. International Journal of Advanced Manufacturing Technology. 77: 383-398

6. Assid M, Gharbi A, Dhouib K (2015) Joint production and subcontracting planning of unreliable multi-facility multi-product production systems. Omega 50 (0):54-69

7. Lee W (2005) A joint economic lot size model for raw material ordering, manufacturing setup, and finished goods delivering. Omega 33 (2):163-174

8. Hajji A, Gharbi A, Kenne JP (2009) Joint replenishment and manufacturing activities control in a two stage unreliable supply chain. International Journal of Production Research 47 (12):3231-3251

9. Song DP (2009) Optimal integrated ordering and production policy in a supply chain with stochastic lead-time, processing-time, and demand. Automatic Control, IEEE Transactions on 54 (9):2027-2041

10. Sana SS (2011) A production-inventory model of imperfect quality products in a three-layer supply chain. Decision Support Systems 50 (2):539-547

11. Berthaut F, Gharbi A, Pellerin R (2009) Joint hybrid repair and remanufacturing systems and supply control. International Journal of Production Research 48 (14):4101-4121

12. Hajji A, Gharbi A, Artiba A Impact of random delay on Replenishment and production control strategies. In: Logistics (LOGISTIQUA), 2011 4th International Conference on, May 31 2011-June 32011 2011. pp 341-348

13. Hajji A, Gharbi A, Kenne JP, Pellerin R (2011) Production control and replenishment strategy with multiple suppliers. European Journal of Operational Research 208 (1):67-74

14. Pal B, Sana SS, Chaudhuri K (2012) Three-layer supply chain - A productioninventory model for reworkable items. Applied Mathematics and Computation 219 (2):530-543

15. Sana SS (2012) A collaborating inventory model in a supply chain. Economic Modelling 29 (5):2016-2023

16. Song DP (2013) Optimal Control and Optimization of Stochastic Supply Chain Systems. Springer London, London

17. Jana D, Maity K, Roy T (2013) A three-layer supply chain integrated productioninventory model under permissible delay in payments in uncertain environments. $\mathrm{J}$ Uncertain Anal Appl 1 (1):1-17

18. Song DP, Dong JX, Xu J (2014) Integrated inventory management and supplier base reduction in a supply chain with multiple uncertainties. European Journal of Operational Research 232 (3):522-536

19. Papachristos S, Konstantaras I (2006) Economic ordering quantity models for items with imperfect quality. International Journal of Production Economics 100 (1):148154

20. Ben-Daya M, Noman SM (2008) Integrated inventory and inspection policies for stochastic demand. European Journal of Operational Research 185 (1):159-169

21. Jiang RY (2013) Equal-risk acceptance sampling plan. Applied Mechanics and Materials 401-403:2234-2237 
22. Moussawi-Haidar L, Salameh MK, Nasr W (2014) Effect of deterioration on the instantaneous replenishment model with imperfect quality items. Applied Mathematical Modelling 38 (24):5956-5966

23. Squeglia NL (2008) Zero acceptance number sampling plans. ASQ Quality Press, Milwaukee, Wis.

24. Schilling EG, Neubauer DV (2009) Acceptance sampling in quality control. 2nd ed. edn. CRC Press, Boca Raton

25. Chattinnawat W (2013) Investigating design of zero acceptance number single sampling plans with inspection errors. International Journal of Quality \& Reliability Management 30 (6):662-674

26. Starbird SA (2001) Penalties, rewards, and inspection: provisions for quality in supply chain contracts. Journal of the Operational Research Society 52 (1):109-115

27. Wan H, Xu X, Ni T (2013) The incentive effect of acceptance sampling plans in a supply chain with endogenous product quality. Naval Research Logistics (NRL) 60 (2):111-124

28. Ben-Daya M, Noman SM, Hariga M (2006) Integrated inventory control and inspection policies with deterministic demand. Computers \& Operations Research 33 (6): $1625-1638$

29. Moussawi-Haidar L, Salameh MK, Nasr W (2013) An instantaneous replenishment model under the effect of a sampling policy for defective items. Applied Mathematical Modelling 37 (3):719-727

30. Sajadi SM, Seyed Esfahani MM, Sörensen K (2011) Production control in a failureprone manufacturing network using discrete event simulation and automated response surface methodology. Int J Adv Manuf Technol 53 (1-4):35-46

31. Rivera-Gomez H, Gharbi A, Kenné JP (2013) Joint control of production, overhaul, and preventive maintenance for a production system subject to quality and reliability deteriorations. Int J Adv Manuf Technol:1-20

32. Assid M, Gharbi A, Hajji A (2014) Joint production and setup control policies: an extensive study addressing implementation issues via quantitative and qualitative criteria. Int J Adv Manuf Technol:1-18

33. Lavoie P, Gharbi A, Kenné JP (2010) A comparative study of pull control mechanisms for unreliable homogenous transfer lines. International Journal of Production Economics 124 (1):241-251

34. Montgomery DC (2013) Design and analysis of experiments. 8th ed.. edn. John Wiley \& Sons, Inc., Hoboken, NJ

35. Law AM (2007) Simulation modeling and analysis. 4th ed.. edn. McGraw-Hill, Boston 